\title{
DISCHARGE DURING WINTER DOES NOT INCREASE DURATION OF OXYGEN THERAPY IN PRETERM BABIES WITH CHRONIC LUNG DISEASE (CLD)
}

\author{
P. Desai, A. Phillips, G. Fox, M. Campbell \\ NICU, Guy's \& St Thomas' NHS Foundation Trust, London, UK
}

Background: Preterm babies with significant CLD may require home oxygen after hospital discharge. Due to the risk of winter viral ilnesses we hypothesised that CLD babies discharged home during winter would require oxygen therapy for longer after discharge.

Methodology: We reviewed our database of babies with CLD discharged home on oxygen between $1 / 1 / 2007$ and 31/12/2010. We compared the age at discharge and duration of home oxygen between babies discharged in summer (April - September) with those in winter (October - March). All babies were managed by the Neonatal Outreach Team and oxygen was weaned according to established unit protocols.

Results: During the study period a total of 74 babies (38 male, 36 female) were discharged home who weaned off oxygen therapy. Mean ( \pm SD) birthweight was $967 \pm 260 \mathrm{~g}$ and gestation $27.3 \pm 2$ weeks. The babies were discharged at a mean gestation of $38.7 \pm 4.6$ weeks and discontinued oxygen at a gestation of $47.7 \pm 13.2$ weeks.

$\mathrm{n}=31$ babies were discharged over winter and $\mathrm{n}=43$ in summer. There were no differences in birthweight and gestation between the two cohorts. Discharge gestation and corrected gestation at discontinuation of oxygen did not differ between the groups. There were no correlations between duration of oxygen therapy and month of discharge or gender.

Conclusion: Home oxygen babies discharged home in winter did not have an increase in hospital length of stay and did not require oxygen for a longer. In contrast to our hypothesis the duration of home oxygen therapy in CLD babies was not affected by the season of discharge. 